\title{
Interprovincial Comparison and Improvement Path Selection for Scientific and Technological Innovation Ability in Liaoning
}

\author{
Lingyan Meng \\ Department of Economics and Management \\ Jining University \\ Qufu, Shandong, 273115, China \\ mly7312@163.com
}

\begin{abstract}
In the past five years, the scientific and technological innovation ability of Liaoning has declined year by year. Using literature research, field research, comparative analysis and expert interviews, this work analyzed the current situation of Liaoning's scientific and technological innovation ability from three aspects, i.e., scientific and technological innovation investment, innovation output and innovation potential, and screened important factors restricting Liaoning's scientific and technological innovation ability. This work proposed several path selections to enhance the comprehensive strength of Liaoning's scientific and technological innovation, to promote transformation and upgrading of Liaoning's industrial structure and to provide theoretical reference as well as reality for revitalization of Liaoning's old industrial bases through increasing innovation investment. The actions are conducive to strengthening dominant position of enterprises, integrating resources with innovation and expanding excavation of innovation potential.
\end{abstract}

Keywords-Innovation investment; Innovation output; Innovation potential; Interprovincial comparison; Collaborative innovation

\section{INTRODUCTION}

Since 2010, Forbes has published the Innovative Competitiveness Ranking List of Chinese Mainland Cities for years. Based on the number of patent applications, the amount of patents authorization, the proportion of science and technology expenditures to local fiscal expenditures, and the number of international patents or PTC applications, it ranks the innovation ability of Chinese mainland cities comprehensively. Among 30 cities listed in 2017, four municipalities, i.e., Beijing, Shanghai, Chongqing and Tianjin ranked 2nd, 3rd, 10th and 17th respectively, Jiangsu, Guangdong, Zhejiang and Anhui had 7, 6, 4 and 2 cities on the list respectively, and capital cities of Sichuan, Shaanxi, Hubei and Henan were also selected. Dalian of Liaoning Province was also listed in 2010-2012, 2014 and 2015, but its ranking has been declining year by year. In 2013 and 2017, it was not on the list, in addition, Shenyang, the provincial capital, has never been on the list. The above data can directly reflect that Liaoning's innovation ability is not only far behind that of developed provinces, but also surpassed by Shaanxi, Anhui, Hubei, Henan and other provinces. How is Liaoning's scientific and technological innovation ability after all? How big is the gap with developed provinces? How can support Liaoning's economy to embark on a path of high-quality and rapid development? How to systematically evaluate and comprehensively enhance Liaoning's scientific and technological innovation ability has become an important research topic, which will both enrich the research results in the existing fields and provide experience and reference for Liaoning's scientific and technological innovation practice.

\section{INTERPROVINCIAL COMPARISON OF LIAONING'S SCIENTIFIC AND TECHNOLOGICAL INNOVATION ABILITY}

In order to accurately evaluate Liaoning's scientific and technological innovation ability and level as well as its impact on economic growth, this work constructed an evaluation index system consisting of three first-level indicators and 19 secondlevel indicators based on sample data of 10 provinces in 2017. Comparative analysis shows that Liaoning's scientific and technological innovation investment is seriously insufficient, its intensity is significantly low, and the output of scientific and technological innovation also has a big gap with the average level of other provinces and the whole Chine. However, there are certain advantages in the potential of scientific and technological innovation. The specific conditions are as follows:

\section{A. Comparison of investment in scientific and technological innovation}

The total amount of innovation input was insufficient, the growth was too slow, and the economic pull was weak [1]. The total $R \& D$ internal expenses of Liaoning were 37.23 billion yuan, ranking 16th in China and accounting for $2.4 \%$ of the national level (1.56767 trillion yuan) and 18.3\% of Guangdong (203.49 billion yuan). From 2011 to 2017, the annual nominal growth rate of Liaoning's R\&D investment was $0.4 \%$, ranking the last in China and only accounting for $3.2 \%$ of the national level (12.6\%). Liaoning's R\&D input intensity was $1.69 \%$, ranking 13th in China, which was $0.42 \%$ lower than the national level (2.11\%) and 0.97\% lower than Jiangsu (2.66\%). Liaoning's R\&D personnel input intensity was $0.88 \%$, which was $0.06 \%$ lower than the national level $(0.94 \%)$, although the 
gap was not large, it was $2.1 \%$ lower than Zhejiang (3.03) and Jiangsu (3.02).

Investment in fiscal technology was insufficient, and the investment structure of scientific and technological innovation was unreasonable. Among the general public budget expenditures of Liaoning, the proportion of scientific and technological expenditure was only $1.35 \%$, ranking 15 th in China, which was $1.07 \%$ lower than the national level $(2.42 \%)$ and $4.18 \%$ lower than Guangdong (5.53\%). The amount of funds and the number of personnel used for experimental development research in Liaoning were less seriously. Only 28.42 billion yuan was used for test development research, ranking the last in 10 provinces, which was only $15.3 \%$ of Jiangsu (185.96 billion yuan). Among the 88,000 R\&D personnel in Liaoning, there were 62,000 people engaged in test development research, ranking the last in 10 provinces, which was only $12.5 \%$ of Jiangsu $(498,000)$, and there were 26,000 people engaged in foundation and application research, ranking 5th in 10 provinces, which was $58 \%$ of 45,000 people in Jiangsu. See Table 1 for details.

From the input structure, Liaoning's R\&D expenditure for test development research accounted for $76.2 \%$ of all $R \& D$ expenditures, which was 17.3\% lower than Zhejiang (93.5\%). Liaoning's R\&D expenditure for foundation and application research accounted for $23.8 \%$, which was $17.3 \%$ higher than Zhejiang (6.5\%). During the same period, the proportion of personnel engaged in experimental development research in Liaoning was $70.8 \%$ of all R\&D personnel, which was $22.7 \%$ lower than Zhejiang (93.5\%). The proportion of R\&D personnel engaged in basic and applied research was $29.2 \%$, which was $22.7 \%$ higher than Zhejiang (6.5\%).

Under the circumstance of insufficient $R \& D$ funds and R\&D personnel, Liaoning had a low proportion of investment in the test development field, which directly hindered the transformation of scientific and technological achievements into real productivity and led to a disconnect between scientific and technological innovation and economic development.

The dominant position of enterprises needed to be strengthened. The dominant position of innovation in Liaoning industrial enterprises ranked at the bottom of the 10 provinces. For the proportion of enterprises with $R \& D$ activities, Liaoning (13.4\%) was $9.6 \%$ lower than the national level (23.0\%) and $26.7 \%$ lower than Jiangsu (40.1\%). For the R\&D input intensity of enterprises, Liaoning $(0.66 \%)$ was $1.51 \%$ lower than the national level (2.17\%), $0.77 \%$ and $0.64 \%$ lower than Zhejiang (1.43\%) and Guangdong (1.30\%), respectively.

For the source of R\&D funding, 29.1\% of Liaoning's innovation investment came from the government, ranking 11th in China, which was 9.1\% higher than the national level (20.0\%) and 22.2\% higher than Shandong (6.9\%). Correspondingly, the proportion of innovation investment in enterprises was $68.9 \%$, which was $7.2 \%$ lower than the national level (76.1\%) and 22.5\% lower than Zhejiang (91.4\%). Compared with the national level and other provinces, the dominant innovation position of Liaoning enterprises was still not outstanding, and it needed to be enhanced.

TABLE I. $\quad$ COMPARISON OF R\&D FUNDS AND PERSONNEL INPUT IN 10 PROVINCES IN 2017 [2]

\begin{tabular}{|c|c|c|c|c|c|c|c|}
\hline Area & $\begin{array}{c}\text { R\&D } \\
\text { internal } \\
\text { expenses }\end{array}$ & $\begin{array}{l}\text { Foundation and } \\
\text { application }\end{array}$ & $\begin{array}{c}\text { Test } \\
\text { development }\end{array}$ & Area & $\begin{array}{l}\mathrm{R} \& \mathrm{D} \text { personnel full time } \\
\text { equivalent }\end{array}$ & $\begin{array}{l}\text { Foundation and } \\
\text { application }\end{array}$ & $\begin{array}{c}\text { Test } \\
\text { development }\end{array}$ \\
\hline Jiangsu & 2026.9 & 167.2 & 1859.6 & Jiangsu & 54.3 & 4.5 & 49.8 \\
\hline Guangdong & 2035.1 & 250.5 & 1784.6 & Guangdong & 51.6 & 6.3 & 45.3 \\
\hline Shandong & 1566.1 & 126.2 & 1439.9 & Zhejiang & 37.7 & 2.4 & 35.2 \\
\hline Zhejiang & 1130.6 & 73.9 & 1056.8 & Shandong & 30.1 & 4.4 & 25.8 \\
\hline Hubei & 600.0 & 99.8 & 500.3 & Fujian & 13.2 & 1.8 & 11.4 \\
\hline Anhui & 475.1 & 59.1 & 416.0 & Anhui & 13.6 & 2.5 & 11.1 \\
\hline Fujian & 454.3 & 41.8 & 412.5 & Hubei & 13.7 & 2.6 & 11.0 \\
\hline Hunan & 468.8 & 62.5 & 406.4 & Hunan & 11.9 & 2.5 & 9.4 \\
\hline Shaanxi & 419.6 & 100.6 & 319.0 & Shaanxi & 9.5 & 2.7 & 6.8 \\
\hline Liaoning & 372.7 & 88.5 & 284.2 & Liaoning & 8.8 & 2.6 & 6.2 \\
\hline
\end{tabular}

B. Comparison of scientific and technological innovation output

The level of tangible output was obviously low, and the scientific and technological innovation was not enough to support economic development. The tangible output level of Liaoning's innovation was very low: in 2017, the proportion of Liaoning's high-tech industries was $4.8 \%$, ranking 25th in China, which was $8.55 \%$ lower than the national level (13.3\%) and $24.4 \%$ lower than Guangdong (29.2\%). The proportion of new products in Liaoning was $8.0 \%$, ranking 17 th in China, which was 7.1\% lower than the national level (15.1) and $24.7 \%$ lower than Zhejiang (32.7\%).

The number of intangible output was seriously less and the competitiveness of science and technology was insufficient. The number of intangible outputs in Liaoning was very small: in 2017, Liaoning (93.9 pieces/10,000) was the least in patent applications, which was $50.8 \%$ of the national level (185.0 pieces/10,000) and only $25.3 \%$ of Zhejiang (370.6 pieces/10,000); Liaoning (44.8 pieces/10,000) was also the least in patent grants, which was $49.2 \%$ of the national level (91.0 pieces/10,000) and only $21.5 \%$ of Zhejiang (208.7 pieces/10,000). 
The overall profitability of industrial enterprises was relatively poor, and the radiation driving function of high-tech industries was not significant [3]. The profit rate of high-tech industries in Liaoning was $7.9 \%$, ranking 13th in China, which was $1.2 \%$ higher than the national level (6.7\%), but 3.8\% lower than Zhejiang (10.5\%). The profit rate of all industrial enterprises in Liaoning was only $4.9 \%$, ranking 24th in China, which was $1.3 \%$ lower than the national level (6.2\%). It could be considered that the level of innovation output in Liaoning was seriously low, the radiation driving effect of other industrial enterprises was weak, the profitability of all industrial enterprises was very poor, and the innovative will of enterprises, institutions and individuals has not been fully exerted, so the number of intangible results was very small, so it was impossible to form an effective pull on economic growth.

\section{Comparison of scientific and technological innovation potential}

The reserve of high-tech talents was insufficient, and the cultivation of high-tech talents was strong, but the problem of brain drain was serious. In terms of high-tech talents reserve, the number of academicians from the two academies (Chinese Academy of Sciences and Chinese Academy of Engineering) owned by Liaoning did not have obvious advantages. According to statistics, Liaoning had 74 academicians from the two academies, accounting for $3.2 \%$ of the total number of academicians (2339) in the two academies across China and ranking 12th in China, only $16.4 \%$ of Jiangsu (450 people).

Liaoning's training ability of high-tech talents had significant advantages. Liaoning (24.1\%) ranked first with Shaanxi for the proportion of students enrolled in higher education, which was $5.6 \%$ higher than the national level (18.5\%). Liaoning (7.9\%) ranked second for the proportion of graduate students, which was $3.2 \%$ higher than the national level (4.7\%), and only $0.8 \%$ lower than Jiangsu (8.7\%). Liaoning's training ability of high-tech talents was always strong, but the proportion of brain drain was high. In 2017, among undergraduate students from Northeastern University and Shenyang Pharmaceutical University as well as postgraduate students from Dalian University of Technology and Liaoning University, the proportion of students staying in Liaoning for employment was 24.1\%, 22.2\%, 16.58\%, and $56.18 \%$, respectively. Most students flowed to Beijing, Guangdong, Shanghai and other developed provinces and cities While paying attention to the cultivation of talents, Liaoning should also try to retain talents and even attract talents to inflow, so that the potential for innovation could be released to the utmost.

The population vitality was obviously insufficient. The ratio of resident population to registered population was 1.18, ranking 6th in 10 provinces, which was 0.05 lower than the national level (1.23) and 0.37 lower than Guangdong (1.55). The difference was significant. Although many colleges and universities in the province were recruiting high-tech talents, preferential policies (such as housing subsidies, housing expenses and research start-up funds) are obviously insufficient, therefore, it was less attractive to high-tech talents compared with developed provinces such as Guangdong and Jiangsu.

\section{PATH SELECTION OF LIAONING TO ENHANCE ITS} SCIENTIFIC AND TECHNOLOGICAL INNOVATION ABILITY

Liaoning has obvious disadvantages in terms of scientific and technological innovation investment and innovation output Problems of insufficient input, unreasonable structure and the dominant position that needs to be strengthened are very prominent. Although Liaoning has certain innovation potential, the brain drain is serious, and the lack of attraction to high-tech talents cannot be ignored. It must propose feasible paths from the perspectives of increasing investment, strengthening the dominant position and promoting collaborative innovation.

\section{A. Expanding sources of funds and increasing investment in test development}

Integrating resources from multiple parties and increasing investment in test development can directly promote digestion and absorption ability of Liaoning's scientific and technological achievements. First, encouraging and guiding the injection of private capital can expand sources of innovative funds, increase the total amount of innovation investment, and enhance the intensity of R\&D investment [4]. Second, adjusting the innovation input structure, focusing on increasing the proportion of investment in test development research, and making full use of all kinds of technology incubator, university-enterprise collaboration innovation alliance and other carriers can strive to increase the conversion rate of scientific and technological achievements and invest a greater proportion of innovation funds in areas that can produce faster and more direct economic benefits. Third, it is necessary to guide financial resources and human input of innovation to incline to aerospace equipment manufacturing and medical instrumentation equipment manufacturing, which should not only base itself on Liaoning's advantageous fields, but also aim at international advanced products and pay close attention to international advanced technologies, making it the mainstay of driving high-quality development of Liaoning's economy.

\section{B. Enhancing vitality of innovation and strengthening the dominant position of enterprises}

Liaoning's enterprises have insufficient innovation intentions and weak abilities, which have insufficient driving force for Liaoning's economy. First, establishing and improving incentive systems such as technology equity system and patent property rights system and creating a fair, transparent and open market environment can reduce burdens and loose bonds for enterprises, reduce their opportunity cost and transaction cost of innovation, and make them dare to innovate and enjoy innovating. Second, creating several indomitable large enterprises and concentrating on supporting science and technology research and development activities of large-scale equipment manufacturing enterprises can change their status of large but not strong, make them develop into leaders and vane of innovation and realize the transformation from "manufacturing" to "intelligent manufacturing". Third, cultivating a group of overwhelming small and medium-sized enterprises with the help of business incubators can help them grow rapidly [5] through financial technology subsidies, tax reductions, innovation fund guidance and service platform construction. 


\section{Integrating resources from multiple parties and promoting collaborative innovation}

There are many universities and research institutes in Liaoning, so it is necessary to integrate various resources at all levels and promote collaborative innovation [6]. First, the establishment of Provincial Committee of Civil-military Integration Development Office and the declaration of Shenyang and Dalian National Civil-military Integration Innovation Demonstration Zone are major opportunities to promote collaborative innovation between the military and the civilian. It will be coordinated by the Provincial Committee of Civil-military Integration Development Office and the Provincial Industry and Information Commission (State Administration of Science, Technology and Industry for National Defense). These departments work together to promote the State Administration of Science, Technology and Industry for National Defense as well as ten military industry enterprises to build science and technology collaborative innovation centers, key laboratories and pilot bases with province's leading research institutes, universities, and enterprises, guide the transformation of advanced military technology into industrialized fields, and enterprises with innovative advantages to participate in the development of cutting-edge military weapons, equipment and product technology, and explore the establishment of a six-in-one military-civilian collaborative innovation service system of "military, politics, enterprise, learning, research and service". Second, it should guide colleges and universities, research institutes and internationally renowned academic institutions to jointly set up a collaborative innovation center to cultivate high-tech talents, tackle world's cutting-edge technologies, and reserve power for Liaoning's future scientific and technological progress and economic development. Third, it should promote colleges and universities and research institutes to set up a collaborative innovation center with enterprises and industrial bases jointly, which is responsible for core common technology research and development, core components production technology development and transformation of scientific and technological achievements.

\section{Innovating talent policy and exploiting the potential of innovation}

Liaoning must constantly expand its innovation "new force" and try to promote the release of innovation potential at a deeper level. First, it can encourage researchers in colleges and universities and research institutes to have innovation and entrepreneurship in a variety of forms, such as part-time and unpaid leave, and give instant rewards to researchers who have achieved scientific research results. Second, it should make every effort to introduce cutting-edge talents and find ways to attract high-tech talents, such as giving priority to undergraduate graduates, entrepreneurship subsidies and rent subsidies, and actively join the competition for talents in second-tier cities to attract talent inflows [7]. Third, it can create an innovative atmosphere, set up an innovative concept that is dare to be in the first and tolerant for failure in the province, provide all the conveniences for the mass innovation and entrepreneurship, inspire the wisdom of all people within the province and jointly shape "innovative Liaoning".

\section{CONCLUSION}

Through comprehensive evaluation and comparative analysis of Liaoning's scientific and technological innovation abilities, it can be found that Liaoning's total investment in innovation is seriously insufficient, the structure is not reasonable, the innovation output is obviously less, the profitability of enterprises is poor, and the brain drain is serious. In terms of innovation potential, it has strong talents training ability and certain comparative advantages. Liaoning must abandon the blind superiority brought about by historical achievements, rationally understand the gaps and causes with advanced provinces based on accurately judging the strength of scientific and technological innovation, grasp the management of scientific and technological innovation, implement the important spirit of "endeavoring in pragmatic way, executing in rigorous way, and implementing in practical way", provide a "green channel" for innovative activities, innovative projects, and innovative enterprises " in links of approval, taxation and credit and offer preferential policies. It should also make more efforts to implement innovative concepts, adjust input structure, stimulate corporate vitality and promote collaborative innovation, so as to make sure that scientific and technological innovation work is implemented, strive to create a strong province of scientific and technological innovation, and give full play to the leading role of scientific and technological innovation in Liaoning's economic development.

\section{REFERENCES}

[1] Ding Yu, Bao Yanfeng. Research on Countermeasures of Improving Scientific and Technological Innovation Ability in Liaoning [J]. Science and Technology Innovation Herald, 2018 (12)

[2] Department of Social Science and Cultural Industry Statistics of National Bureau of Statistics. China Statistical Yearbook on Science and Technology - 2018: [M]. Beijing: China Statistics Press, 2018 (12)

[3] Hu Yuhan. Countermeasures for Transformation and Upgrading of Local Traditional Industries Driven by Innovation-Taking Anshan City as an Example [J]. Pioneering with Science and Technology Monthly, 2018 (07)

[4] Bai Yuguang. Research on Measurement and Promotion Strategy of Innovative Enterprises' Scientific and Technological Innovation Ability Taking Liaoning Province as an Example[J]. Productivity Research, 2015(04)

[5] Chi Guotai, Zhao Zhichong. Construction of the Evaluation Index System of Scientific and Technological Innovation Based on Enterprises[J]. Research Management, 2018(03)

[6] Wang Dongsheng. Research on Collaborative Innovation of Industry, University and Research in Liaoning's Advantageous Industries [J] National Circulation Economy, 2018 (10)

[7] Su Zhiwen. Research on the Impact of Scientific and Technological Talent Agglomeration on the Technological Innovation Efficiency of High-tech Industry [M]. Shandong: Shandong University of Finance and Economics, 2019 (05) 